\title{
Genetic diversity analysis of barley landraces and cultivars in the Shanghai region of China
}

\author{
Z.-W. Chen ${ }^{1,2 *}$, R.-J. Lu ${ }^{1,2 *}$, L. Zou ${ }^{1,2}$, Z.-Z. Du ${ }^{1,2}$, R.-H. Gao ${ }^{1,2}$, T. He ${ }^{1,2}$ \\ and J.-H. Huang ${ }^{1,2}$ \\ ${ }^{1}$ Department of Plant Cell Engineering, Institute of Biotech Research, \\ Shanghai Academy of Agricultural Sciences, Shanghai, China \\ ${ }^{2}$ Department of Plant Cell Engineering, \\ Shanghai Key Laboratory of Agricultural Genetics and Breeding, \\ Shanghai, China \\ *These authors contributed equally to this study. \\ Corresponding author: J.-H. Huang \\ E-mail: plantmolecularbreeding@yahoo.cn
}

Genet. Mol. Res. 11 (1): 644-650 (2012)

Received July 20, 2011

Accepted December 1, 2011

Published March 16, 2012

DOI http://dx.doi.org/10.4238/2012.March.16.2

\begin{abstract}
We analyzed the genetic diversity of 115 barley germplasms, including 112 landraces and three new barley cultivars grown in the Shanghai region, using a set of 11 SSR markers. Sixtysix alleles were observed at the 11 SSR loci, ranged from three to ten, with a mean of six alleles per locus. The polymorphism information content ranged from 0.568 to 0.853 , with a mean of 0.732 , indicating considerable genetic variation in barley in the Shanghai area. Clustering analysis indicated that these barley accessions could be divided into two categories (A and B). Ninety-seven six-rowed barley cultivars were classified in the A category; sixteen two-rowed and two six-rowed barley cultivars were classified in the B category. This demonstrated genetic differences between two-rowed and six-rowed barley varieties. In addition, we found that the three new barley cultivars are closely related.
\end{abstract}

Key words: Barley landraces; Hordeum vulgare; Genetic diversity; SSR markers; PIC 


\section{INTRODUCTION}

Farmer preference and breeder selection create a narrow germplasm base (Duvick, 2005). Some elite germplasms are often used as parents for the next cycle of breeding (Graner et al., 1994). As a result, it leads to greater genetic uniformity and germplasm disappearance. To assure the safety of crop production, it is necessary to extend genetic background in crop breeding. It is well known that genetic diversity is the basis of biological diversity, and thus, it plays a key role in future breeding progress (Yao et al., 2007).

Barley is a cash crop, being the fourth most important cereal crop in the world, where it is used for brewing malts, animal feed and human consumption (Hayes et al. 2002). Barley is widely grown in various environments in China, including the Shanghai area. Once upon a time, there were many barley landraces in the Shanghai area. As we know, the original landraces represent a vast array of germplasms, which can be used in barley breeding for improving biotic or abiotic resistance, nutritional quality, and other traits of interest (Yao et al., 2007). Therefore, the protection and utilization of barley landraces will be more important for us.

The development of molecular markers makes it easy to assess genetic diversity in crops at the DNA level (Reif et al., 2003). Molecular markers such as RAPD (Fernández et al., 2002; Meszaros et al., 2007), AFLP (Zhang and Ding, 2007), ISSR (Fernández et al., 2002), STS (Meszaros et al., 2007), and SSR (Turuspekov et al., 2001; Matus and Hayes, 2002; Feng et al., 2006; Meszaros et al., 2007; Zhang et al., 2007) can be used to estimate genetic diversity.

There have been many studies on genetic diversity in barley (Graner et al., 1994; Turuspekov et al., 2001; Matus and Hayes, 2002; Fernández et al., 2002; Feng et al., 2006; Meszaros et al., 2007; Zhang et al., 2007; Zhang and Ding, 2007; Mikel and Kolb, 2008); however, little is known about the genetic diversity in barley landraces, especially for barley landraces from the Shanghai area. SSRs are codominant, abundant, and informative and their detection is very simple (Matus and Hayes, 2002). This makes them an excellent molecular marker system for analysis of genetic diversity. In this study, we used a set of SSRs from seven linkage groups of barley to survey 112 accessions of barley landraces and 3 new barley cultivars from the Shanghai area. The objectives of this study were i) to estimate genetic diversity of a group of barley landraces from the Shanghai area, ii) to reveal the relationship between the present major cultivars and the landraces in the Shanghai area, and to provide a basis for barley improvement in Shanghai, and iii) to protect the barley landraces of the Shanghai area by genetic classification.

\section{MATERIAL AND METHODS}

\section{Plant materials}

A total of 112 barley landraces from the Shanghai area and 3 barley cultivars, which are the major barley cultivars in the Shanghai area, were used in this study (Table 1). The barley landraces were provided by Shanghai Agrobiological Gene Center, and the 3 new barley cultivars were bred by our group.

\section{Genomic DNA extraction}

Ten seeds of each genotype were sown, and the seedlings were grown in a room at 
room temperature. Two weeks later, approximately $100 \mathrm{mg}$ young leaves of each genotype was used for DNA extraction. The DNA extraction was carried out according to Dellaporta et al. (1983). DNA quality and concentration were estimated using NanoDrop ND-100. DNA samples were then diluted to a concentration of $100 \mathrm{ng} / \mu \mathrm{L}$ using $\mathrm{ddH}_{2} \mathrm{O}$ and stored at $-20^{\circ} \mathrm{C}$.

\begin{tabular}{|c|c|c|c|c|c|c|c|}
\hline Code & Name & Code & Name & Code & Name & Code & Name \\
\hline 1 & Sanyuehuang1 & 31 & Zidamai2 & 61 & Baoshanlaolaibai & 91 & Congmingheiliuzhu \\
\hline 2 & Zidamail & 32 & Shanghaizidamai & 62 & Wusongdamail & 92 & Bailiuzhuyuanmai \\
\hline 3 & Xingshandamai & 33 & Shanghailiulengzidamai & 63 & Shanghaibendidamai & 93 & Shanghaibailiuzhu \\
\hline 4 & Qianqiandamai & 34 & Zidamai3 & 64 & Shanghaidongyangdamai & 94 & Jiadinghongjinliuzhutou \\
\hline 5 & Zaohuangdamai & 35 & Xiaodamai & 65 & Baoshanliulengdamai & 95 & Jiadinghongjinyuanmai \\
\hline 6 & Luocihongmangdamai & 36 & Shanghaixiaodamai & 66 & Qingpuhongdamai & 96 & Liuzhutou \\
\hline 7 & Aizaosan & 37 & Laotuoxul & 67 & Chundamai & 97 & Hongjinliuzhutou1 \\
\hline 8 & Humaiyihao & 38 & Laotuoxu2 & 68 & Liuzhutouzidamai & 98 & Hongjinliuzhutou2 \\
\hline 9 & Baoshanerleng & 39 & Laotuosui & 69 & Liulengzidamai & 99 & Hongjinliuzhutou3 \\
\hline 10 & Daerdamai & 40 & Wanlaotuoxu & 70 & Liulengdamai1 & 100 & Hongjinliuzhutou4 \\
\hline 11 & Bendamail & 41 & Zaolaotuoxu & 71 & Wusongdamai2 & 101 & Liuzhutouyuanmai \\
\hline 12 & Bendamai2 & 42 & Chuanshalaotuoxu & 72 & Liuzhutouhongdamai & 102 & Benyuanmai \\
\hline 13 & Shuanglengbendamai & 43 & Songjianglaotuoxul & 73 & Shanghailaotuoxu1 & 103 & Shanghaisanyuehuang4 \\
\hline 14 & Hongdamai & 44 & Songjiangzaolaotuoxu & 74 & Baoshanlaotuoxu & 104 & Baisanyuehuang \\
\hline 15 & Yangdamai & 45 & Songjianglaotuoxu2 & 75 & Shanghaishuanglengbiandamai & 105 & Shanghaiciguqing \\
\hline 16 & Hongjinerlengdamai & 46 & Wandamail & 76 & Shanghaiyoumangbendamai & 106 & Shanghaisizhutoul \\
\hline 17 & Qingpuerlengdamai & 47 & Wandamai2 & 77 & Bendiyuanmai & 107 & Shanghaisizhutou2 \\
\hline 18 & Dongyangdamai & 48 & Chuanshawandamail & 78 & Bendiguangyuanmai & 108 & Shanghailaotuoxu2 \\
\hline 19 & Bianjidamai & 49 & Chuanshawandamai2 & 79 & Sizhutouyuanmail & 109 & Wumangdamai \\
\hline 20 & Eryuehuang & 50 & Jiadingwandamai & 80 & Sizhutouyuanmai2 & 110 & Liulengdamai2 \\
\hline 21 & Sanyuehuang2 & 51 & Zaodamail & 81 & Fengxiansizhutou & 111 & Sandunhongsileng \\
\hline 22 & Sanyuehuang3 & 52 & Zaodamai2 & 82 & Sizhutoubenyuanmai & 112 & Bailiuzhu \\
\hline 23 & Sanyuehuang4 & 53 & Fengxianzaodamail & 83 & Cigubaiyuanmai & 113 & Hua30 \\
\hline 24 & Shanghaisanyuehuang1 & 54 & Fengxianzaodamai2 & 84 & Shanghaisanyuehuang3 & 114 & Hual1 \\
\hline 25 & Shanghaisanyuehuang2 & 55 & Jiadingzaodamai & 85 & Ciguqingyuanmai & 115 & Hua22 \\
\hline 26 & Baoshansanyuehuang & 56 & Zhongdamai & 86 & Shanghaidenglongtou & & \\
\hline 27 & Hongsanyuehuang & 57 & Damai & 87 & Jiadingliuzhutou & & \\
\hline 28 & Youmangdamai & 58 & Jinshandamai & 88 & Cimaomai & & \\
\hline 29 & Shanghaiyoumangdamai & 59 & Laolaibail & 89 & Heiliuzhuyuanmail & & \\
\hline 30 & Huoshaotoudamai & 60 & Laolaibai2 & 90 & Heiliuzhuyuanmai2 & & \\
\hline
\end{tabular}

\section{SSR analysis}

A total of 28 SSR markers (Table 2) were selected for genotype identification according to Zhang et al. (2007). Three replicate DNA extractions from leaves of each genotype were used to assess the consistency of the band profiles. SSR amplifications were repeated at least three times and only the repetitive PCR products were scored.

\begin{tabular}{|c|c|c|c|c|c|c|c|}
\hline Chr. & SSR marker & Chr. & SSR marker & Chr. & SSR marker & Chr. & SSR marker \\
\hline \multirow[t]{4}{*}{ Chr. 1} & Bmac213 & Chr. 3 & HVLTPPB & Chr. 5 & scssr02306 & Chr. 7 & Bmag206 \\
\hline & Bmag0345 & & Bmag603 & & EBmac0970 & & GBM1464 \\
\hline & Bmag0105 & & BMAG0841 & & Bmac0303 & & Bmag0321 \\
\hline & Bmag0579 & & EBmac541 & & HvLOX & & Bmac0156 \\
\hline \multirow[t]{4}{*}{ Chr. 2} & Bmac0134 & Chr. 4 & GBM1465 & Chr. 6 & Bmac0316 & & \\
\hline & Bmag0692 & & EBmac0775 & & Bmag500 & & \\
\hline & Bmag 140 & & EBmac679 & & Bmac602 & & \\
\hline & GBM1437 & & GBM1324 & & GBM1404 & & \\
\hline
\end{tabular}


PCR was carried out in a $25-\mu \mathrm{L}$ volume containing $1 \mu \mathrm{L} 100 \mathrm{ng} / \mu \mathrm{L}$ genomic DNA template, $2.5 \mu \mathrm{L}$ 10X PCR buffer containing $15 \mathrm{mM} \mathrm{Mg}^{2+}, 0.5 \mu \mathrm{L} 10 \mathrm{mM}$ dNTP mixture, $0.75 \mathrm{U}$ Taq DNA polymerase, and $0.75 \mu \mathrm{L} 10 \mu \mathrm{M}$ forward and reverse primers. Depending on the primer pair used, DNA amplification was performed in a 2720 thermocycler (ABI, USA) with a preliminary step of 5 min at $94^{\circ} \mathrm{C}$, followed by 40 cycles of $30 \mathrm{~s}$ at $94^{\circ} \mathrm{C}, 30 \mathrm{~s}$ at $50-60^{\circ} \mathrm{C}$ and $30 \mathrm{~s}$ at $72^{\circ} \mathrm{C}$ and a final 6 -min extension at $72^{\circ} \mathrm{C}$. Next, $2.5 \mu \mathrm{L} 98 \%$ formamide electrophoresis loading buffer containing $0.25 \%$ $(\mathrm{w} / \mathrm{v})$ bromophenol blue and $0.25 \%(\mathrm{w} / \mathrm{v})$ xylene cyanole $\mathrm{FF}$ was added to the reactants of each reaction. After denaturation, the PCR products were separated on $8 \%$ denaturing polyacrylamide gels using $8 \mathrm{M}$ urea and $1 \mathrm{X}$ TBE buffer at constant voltage $(200 \mathrm{~V})$ for about $2 \mathrm{~h}$. A 700 -bp DNA ladder ranging from 25 to $700 \mathrm{bp}$ was used as a size standard. DNA fragments were visualized following silver staining according to the method of Sanguinetti et al. (1994).

\section{Data analysis}

Data obtained from SSR analysis were scored as presence (1) or absence (0) of fragments for each barley genotype, and polymorphism information content (PIC) was calculated from the following formula (Anderson et al., 1993).

$$
\mathrm{PIC}_{\mathrm{i}}=1-\sum_{\mathrm{j}=1}^{\mathrm{n}} \mathrm{P}^{2} \mathrm{ij},
$$

where $P i j$ is the frequency of the $j^{\text {th }}$ SSR allele for the $i^{\text {th }}$ marker, and is summed over $n$ alleles. The dendrogram was constructed by UPGMA cluster analysis using the simple matching coefficient (SM) (Sneath and Sokal, 1973) and NTSYS-pc version 2.10 package (Rohlf, 2002).

\section{RESULTS}

\section{SSR amplification and PIC statistics}

In this study, 28 SSR markers were adopted for SSR analysis, and 12 of them with clear and steady bands were chosen for statistics, of which 11 were polymorphic among 115 barley germplasms. A total of 66 alleles were observed at the 11 SSR loci, ranging from 3 to 10 with an average of 6 (Table 3), and PIC values ranged from 0.568 to 0.853 with an average of 0.732 .

\begin{tabular}{l} 
Table 3. Polymorphic SSR markers and the polymorphism information content (PIC). \\
\begin{tabular}{lcccc}
\hline SSR marker & Chr. & Total alleles & Polymorphic alleles & PIC \\
\hline Bmac213 & 1 & 7 & 7 & 0.79 \\
Bmag0579 & 1 & 5 & 2 & 0.75 \\
Bmac0134 & 2 & 8 & 8 & 0.82 \\
EBmac0775 & 4 & 7 & 7 & 0.74 \\
EBmac679 & 4 & 4 & 5 & 0.72 \\
GBM1324 & 4 & 5 & 4 & 0.67 \\
Bmac0303 & 4 & 6 & 5 & 0.72 \\
HvLOX & 5 & 10 & 3 & 0.67 \\
Bmag500 & 5 & 3 & 10 & 0.85 \\
Bmac602 & 6 & 6 & 1 & 0.75 \\
GBM1404 & 6 & 5.18 & 0.57 \\
Mean & 6 & &
\end{tabular} \\
\hline
\end{tabular}




\section{Dendrogram obtained with SSR markers}

The dendrogram (Figure 1) obtained using the SM coefficient consisted of two main categories (A and B). The A category was divided into two subgroups (A1 and A2). In addition, the $A 1$ subgroup was further divided into two subclasses $\left(A_{11}\right.$ and $\left.A_{12}\right)$. On the dendrogram, the 3 new two-rowed barley cultivars (Hua30, Hua11 and Hua22) were all in the B category, and they were linked very close. Except for accessions 27 and 28, all accessions in the B category were two-row barley, while all accessions in the A category were six-row barley.

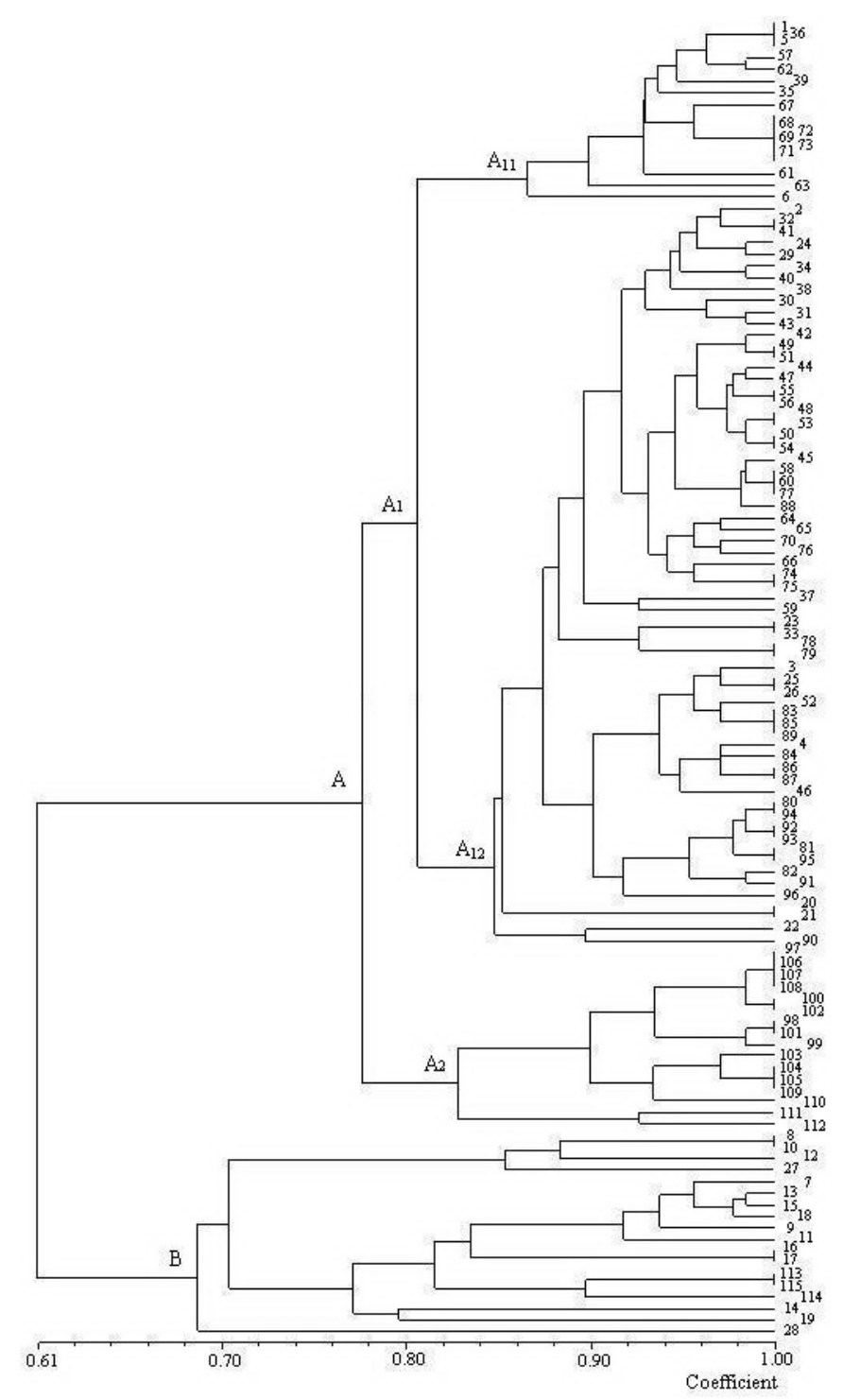

Figure 1. Dendrogram showing the genetic relationships of 115 barley germplasms based on SSR markers. 


\section{DISCUSSION}

\section{SSR markers in barley genetic diversity analysis}

In this study, we just chose 11 SSR markers for barley genetic diversity analysis (Table 3), and they were from $\mathrm{Chr} .1, \mathrm{Chr} .2, \mathrm{Chr} .4, \mathrm{Chr}$. 5, and $\mathrm{Chr}$. 6. Considering the low coverage of the whole genome, it was disadvantageous to analyze barley genetic diversity. However, we still obtained many alleles, and most of them were polymorphic. Although some barley germplasms were not discriminated by the cluster analysis (Figure 1), the general classification was successful, especially for two-row and six-row barley. It indicated that the genetic structure of barley germplasms in the Shanghai area was high, and the genetic background was different between two-row and six-row barley. Therefore, we inferred that the SSR marker was a kind of high efficiency molecular marker for barley genetic analysis and could reveal the genetic differences of barley germplasms as described in previous studies (Saghai Maroof et al., 1994; Struss and Plieske, 1998; Turuspekov et al., 2001; Matus and Hayes, 2003; Feng et al., 2006; Zhang et al., 2007; Mikel and Kolb, 2008).

\section{Genetic diversity for barley germplasm protection and barley breeding}

Cluster analysis did not clearly identify all the barley germplasms (Figure 1). There maybe two reasons, one is that the SSR markers we used were not enough to discriminate all the germplasms, and the other is that some germplasms were duplicated in the collection of barley landraces of the Shanghai area and were stored for a long time and that there might have been some error. Therefore, SSR markers appear to provide an optimal system to identify duplicate materials in the barley germplasm collection (Struss and Plieske, 1998), and they are helpful in protecting and managing the barley collections.

In addition, we found that the genetic relationships of three new barley cultivars were very close, especially for the accessions 113 and 115 . This may cause disadvantages for barley production in the Shanghai area. While there are many barley landraces in the Shanghai area, they have a variety of traits for adaptation in this region. Thus, they will provide many excellent characters for barley breeding in the future and will promote the development of better and more secure barley production in Shanghai and surrounding areas.

\section{SSR markers in new variety protection}

As we know, molecular fingerprinting is an effective and accurate way to identify crop varieties (Nandakumar et al., 2004). In this study, we found that the SSR marker Bmac0303 could distinguish the 3 new barley cultivars from other barley landraces, and we could then protect the breeder rights of the 3 barley cultivars by this locus. Similarly, we could identify all barley landraces by SSR fingerprinting, and we would then find out whether there were preservation repeats or mistakes for varieties. Therefore, we could protect these barley landraces better by SSR fingerprinting.

\section{ACKNOWLEDGMENTS}

Research supported by the Earmarked Fund for Modern Agro-Industry Technology Research System (CARS-05), Ministry of Agriculture of China, the Key Program of Basic 
Research of Shanghai Municipal S\&T Commission of China (\#09JC1412800) and the Project No. 2-1 from Science and Hightech Based Major Program of Agriculture Committee of Shanghai Municipal Administration (Project \#2009 2-1). We would like to thank Shanghai Agrobiological Gene Center for providing barley landraces of the Shanghai area. We are also grateful to Professor Zaochang Liu at the Shanghai Agrobiological Gene Center and Dr Mingzhe Yao at the Tea Research Institute, Chinese Academy of Agricultural Sciences for their assistance with data analysis.

\section{REFERENCES}

Anderson JA, Churchill GA, Autrique JE, Tanksley SD, et al. (1993). Optimizing parental selection for genetic linkage maps. Genome 36: 181-186.

Dellaporta SL, Wood J and Hicks JB (1983). A plant DNA minipreparation: version II. Plant Mol. Biol. Rep. 1: 19-21.

Duvick DN (2005). The contribution of breeding to yield advances in maize (Zea mays L.). Adv. Agron. 86: 83-145.

Feng ZY, Liu XJ, Zhang YZ and Ling HQ (2006). Genetic diversity analysis of Tibetan wild barley using SSR markers. Yi. Chuan Xue. Bao. 33: 917-928.

Fernández M, Figueiras A and Benito C (2002). The use of ISSR and RAPD markers for detecting DNA polymorphism, genotype identification and genetic diversity among barley cultivars with known origin. Theor. Appl. Genet. 104: 845-851.

Graner A, Ludwig WF and Melchinger AE (1994). Relationships among European barley germplasm: II. Comparison of RFLP and pedigree data. Crop Sci. 34: 1199-1205.

Hayes PM, Castro A, Marquez-Cedillo L, Corey A et al. (2002). Genetic Diversity for Quantitatively Inherited Agronomic and Malting Quality Traits. In: Diversity Barley (Von Bothmer R, Knupfeer H, van Hintum T and Sato K, eds.). Elsevier Science Publishers, Amsterdam.

Mikel MA and Kolb FL (2008). Genetic diversity of contemporary North American barley. Crop Sci. 48: 1399-1407.

Matus IA and Hayes PM (2002). Genetic diversity in three groups of barley germplasm assessed by simple sequence repeats. Genome 45: 1095-1106.

Meszaros K, Karsai I, Kuti C, Banyai J, et al. (2007). Efficiency of different marker systems for genotype fingerprinting and for genetic diversity studies in barley (Hordeum vulgare L.). S. Afr. J. Bot. 73: 43-48.

Nandakumar N, Singh AK, Sharma RK, Mohapatra T, et al. (2004). Molecular fingerprinting of hybrids and assessment of genetic purity of hybrid seeds in rice using microsatellite markers. Euphytica 136: 257-264.

Prevost A and Wilkinson MJ (1999). A new system of comparing PCR primers applied to ISSR fingerprinting of potato cultivars. Theor. Appl. Genet. 98: 107-112.

Reif JC, Melchinger AE, Xia XC, Warburton ML, et al. (2003). Genetic distance based on simple sequence repeats and heterosis in tropical maize populations. Crop Sci. 43: 1275-1282.

Rohlf FJ (2002). NTSYS-pc. Numerical Taxonomy and Multivariate Analysis System, Version 2.10. Exeter Software, New York.

Saghai Maroof MA, Biyashev RM, Yang GP, Zhang Q, et al. (1994). Extraordinarily polymorphic microsatellite DNA in barley: species diversity, chromosomal locations, and population dynamics. Proc. Natl. Acad. Sci. U. S. A. 91: 5466-5470.

Sanguinetti CJ, Dias NE and Simpson AJ (1994). Rapid silver staining and recovery of PCR products separated on polyacrylamide gels. Biotechniques 17: 914-921.

Sneath PHA and Sokal RR (1973). Numerical Taxonomy. The Principles and Practice of Numerical Classification. W.H. Freeman and Co., San Francisco.

Struss D and Plieske J (1998). The use of microsatellite markers for detection of genetic diversity in barley populations. Theor. Appl. Genet. 97: 308-315.

Turuspekov Y, Nakamura K, Yoshikawa R and Tuberosa R (2001). Genetic diversity of Japanese barley cultivars based on SSR analysis. Breed. Sci. 51: 215-218.

Yao Q, Yang K, Pan G and Rong T (2007). Genetic diversity of maize (Zea mays L.) landraces from southwest China based on SSR data. J. Genet. Genomics 34: 851-859.

Zhang D and Ding Y (2007). Genetic diversity of wild close relatives of barley in Tibet of China revealed by AFLP. Yi. Chuan 29: 725-730.

Zhang DL, Gao HY and Li SP (2007). Analysis of genetic diversity on beer barley varieties in China by SSR. Acta Agr. Boreali-Occidentalis Sin. 16: 72-76. 